\title{
Educación ciudadana en Colombia: políticas de la exclusión ${ }^{\star}$
}

CITIZENSHIP EDUCATION IN COLOMBIA

EDUCAÇĀo CIDADĀ EM COLÔMBIA: POLITICAS DA EXCLUSĀO

Diego Hernán Arias Gómez ** / dhariasg@udistrital.edu.co

\section{Resumen}

El presente escrito es una reflexión sobre las políticas educativas colombianas que prescriben la formación ciudadana. La argumentación se construye a partir de la constante relación que hay entre la escuela, la conformación del Estado-nación y la comprensión de la ciudadanía como una construcción social que media dicha relación. Se miran los lineamientos educativos y los estándares en función del modelo de ciudadano y de sociedad en vigencia.

\section{Summary}

This paper is a reflection on the educational policies which prescribe Colombian citizenship education. The argument is built on the ongoing relationship between the school, the nation-state formation and the understanding of citizenship as a social construct that mediates this relationship. The educational guidelines and standards based on the citizen model and society in effect, are taking into account.

\section{Resumo}

Este trabalho é uma reflexão ao redor das políticas educativas colombianas que prescrevem a formação cidadã. $\mathrm{O}$ argumento é construido sobre a base da relação existente entre a escola, a formação do Estado-nação e a compreensão da cidadania como uma construção social que medeia esta relação. Eles olham para as diretrizes e padrões educacionais, dependendo do modelo de cidadão e da sociedade em vigor.
Palabras clave

Ciudadanía, formación ciudadana, educación ciudadana, competencias ciudadanas.

\section{Key words}

Citizenship, Citizenship Education, Citizenship Formation, Citizenship Competences.

\section{Palavras chave}

Cidadania, educação cívica, educação para a cidadania, noções de cidadania.

* El presente escrito trae algunos elementos teóricos de la investigación de tesis de doctorado titulada "Identidad nacional y escuela. Imaginarios sociales de estudiantes", desarrollada por el autor y dirigida por Alexander Ruiz.

** Docente de la Universidad Distrital Francisco José de Caldas. Estudiante Doctorado Interinstitucional en Educación sede Universidad Pedagógica Nacional. 
Al consistir en derechos y deberes, la ciudadanía enriquece la subjetividad y le abre nuevos horizontes de autorrealización pero, por otro lado, lo hace por la vía de los derechos y deberes generales y abstractos que reducen la individualidad a lo que hay de universal en ella, transforma los sujetos en unidades iguales e intercambiables en el interior de administraciones burocráticas públicas y privadas, receptáculos pasivos de estrategias de producción, en cuanto fuerza de trabajo, de estrategias de consumo, en cuanto consumidores, $y$ de estrategias de dominio, en cuanto ciudadanos de la democracia de masas

(Santos, 1998, p. 291).

\section{La escuela y la sociedad}

La escuela, desde su nacimiento como sistema, ha sido un instrumento privilegiado para forjar identidades, bajo el entendido que las incipientes unidades nacionales requirieron distintos artefactos culturales para configurar los sujetos que las habitaran. Esta tarea tuvo, en América Latina, la particularidad que el Estado creció más rápido que la nación en la medida que las nuevas repúblicas (unidades jurídicopolíticas y territoriales) se impusieron por encima de fronteras étnicas, culturales o históricas, lo que condujo a que los pobladores se identificaran con su localidad y "sus tradiciones más que con la nueva configuración política" (Siede, 2007, p. 67). La escuela, hija de la ilustración, encargada por tanto de emancipar al individuo por la vía del conocimiento universal, aterrizó en nuestros contextos bajo la expectativa de responder también al ideal romántico de forjar la nación. En esta tensión, la gesta educadora estuvo en sus inicios menos permeada por la lógica de la ilustración de lo que se podría pensar, pues con la consigna de 'civilizar a los bárbaros' se levantaron en la mayoría de países latinoamericanos junto a redes ferroviarias y conglomerados urbanos, multitud de edificios escolares que no sólo transformaron el viejo paisaje arquitectónico, sino que contribuyeron decisivamente a configurar al poblador que estuviera en condiciones de habitar aquella nueva sociedad.

Esta tarea civilizatoria liderada por las elites criollas, se efectuó a favor de ciertas ideas de progreso y desarrollo y contra ingentes masas que habitaban el territorio y que con sus costumbres, prácticas y creencias operaban en la práctica como obstáculo o freno en la intención de sembrar una nueva cultura. Al decir de Isabelino Siede "en la matriz civilizatoria, para domesticar al otro, primero hubo que vencerlo en la batalla y luego fue necesario 'ningunearlo', verlo como irracional y asocial. Por eso, civilizar ha sido, al mismo tiempo, una posibilidad de provisión y expropiación, donde todo lo que la escuela ha posibilitado descansa sobre lo que imposibilitó" (2007, p. 73). Imposibilidad que se tradujo primero en negar la raza, la herencia, la lengua, las costumbres, para posibilitar el progreso, la humanidad, la ciudadanía y la ciencia. En palabras de Villavicencio (2003) esta negación del pueblo real en pos de un pueblo ideal condujo a las elites nacionales a la comprensión de la emancipación como proceso civilizador "porque la incorporación de nuevos hábitos de pensamiento y de acción cobraba en ellos el significado de ponerse a la altura de la civilización, liberando al pueblo de esas otras cadenas que los perpetuaban en la situación de atraso y de anarquía" (p. 86).

En este marco se entiende un texto de principios del siglo XX, de Sarmiento, quien afirmara para Argentina:

Es un hecho fatal que los hijos sigan las tradiciones de sus padres, y que el cambio de civilización, de instintos y de ideas no se haga sino por cambio de razas. ¿Qué porvenir aguarda a Méjico, al Perú, Bolivia y otros Estados sudamericanos que tienen aún vivas en sus entrañas como no digerido alimento, las razas salvajes o bárbaras indígenas que absorbió la colonización, y que conservan obstinadamente sus tradiciones de los bosques, su odio a la civilización, sus odios primitivos y sus hábitos de indolencia y de repugnancia desdeñosa contra el vestido, el aseo, las comodidades y los usos de la vida civilizada? ¿Cuántos años, si no siglos, para levantar aquellos espíritus degradados, a la altura de hombres cultos, y dotados del sentimiento de su propia dignidad? (Sarmiento [1915], citado por Siede, 2007, p. 70).

Bajo este entendido la preocupación por el ciudadano en la escuela latinoamericana fue subsidiario de un proyecto político-pedagógico explícito. El hombre limpio, correctamente hablado, diestro, creyente, respetuoso de los símbolos patrios, obediente, heterosexual, en suma civilizado, marcó históricamente el derrotero de lo significó ser buen ciudadano y por tanto prototipo de estudiante. Así, la ciudadanía en la escuela operó, fundamentalmente desde finales del siglo XIX, como instrumento pedagógico privilegiado para catalizar la cultura política dominante en este escenario social específico.

Civilización que se homologa al ideario europeo, que define a partir de sus formas, prácticas, costumbres y 
conocimientos el camino a seguir, como bien lo indicaban los libros de texto colombianos de aquella época:

Si comparamos los organismos del europeo y el norteamericano con los del colombiano, descubrimos que aquellos son más elásticos, porque aunque no se trasladen están sometidos a los cambios periódicos de temperatura y presión atmosférica que producen las estaciones; y que eso trae consigo no sólo una mayor agilidad muscular para la industria, sino también una gran inclinación a las disciplinas artísticas y científicas de donde salen los mejores inventos de la humanidad y las normas para triunfar en el concierto económico (Libro de texto de geografía [1937], citado por Herrera, Pinilla y Suaza, 2003, p. 134).

En este contexto, citado por Melo (1989), el representante de la elite de la época Laureano Gómez dio su versión negativa de la mezcla de razas, sugiriendo un blanqueamiento de la sangre al decir que el colombiano, por mestizo "no constituye un elemento utilizable para a unidad política y económica de América Latina: conserva demasiado los elementos indígenas: es falso, servil, abandonado y repugna todo esfuerzo y trabajo. Sólo en cruces sucesivos de estos mestizos primarios con europeos se manifiesta la fuerza de caracteres adquirida por el blanco" (p. 87) e indicó que el elemento negro comporta una tara, pues países donde ellos han desaparecido como Argentina, Chile o Uruguay pudieron establecer una sólida organización política y económica. El mismo autor menciona, sin embargo, que esta posición no era homogénea ya que algunos intelectuales del país, como Jorge Bejarano, Alfonso Castro y Armando Solano, vieron la debilidad de las razas no como una degeneración sino como producto de procesos históricos y culturales explicables. Sin abandonar cierto tono racista propugnaron por la defensa de indígena y vieron en la higiene y en la educación los instrumentos privilegiados para su progreso.

La ligazón entre cultura política1 y ciudadanía 2 no es casual y mientras la escuela fue escenario socializador privile-

1 Es el conjunto de prácticas y representaciones en torno al orden establecido, a las relaciones de poder, a las modalidades de participación, a las jerarquías y a las confrontaciones en los diferentes momentos históricos (Herrera y otros, 2005, p. 34). Por su parte para Escobar, Álvarez y Dagnino es "el ámbito de las prácticas y las instituciones, conformadas a partir de la totalidad de la realidad social" (2001, p. 26).

2 Entendida con Boaventura Santos (1998) no sólo como el conjunto abstracto de derechos y deberes sino también como un dispositivo burocrático-administrativo que produce subjetividades. giado, la segunda funcionó como bisagra efectiva para encarnar en los escolares improntas subjetivas modernas en el marco de las demandas de los Estados-nación en formación. Muchos autores legitimaron y legitiman esta unión, esta suerte de lectura funcionalista de la ciudadanía:

En tanto que la educación es formadora de individuos y fundamento de un orden social, el discurso acerca de la ciudadanía tiene mucho que exigirle: qué modelo de ciudadano construir, decidir qué condiciones de esa formación le facultan para ejercer sus derechos, concienciarle de sus obligaciones, determinar qué capacidades, actitudes y comportamientos han de desarrollarse y cuáles no, seleccionar qué imágenes de los demás han de fundamentase y cuáles han de suprimirse, discernir que modos de vida son deseables en la sociedad y en las instituciones... (Gimeno, 2003, p. 20).

En este esquema de restricciones, la ciudadanía fue la figura legal que le permitió a los Estados entender y tramitar las relaciones con algunos de sus pobladores. No todos eran ciudadanos. Filtros de patrimonio, de sexo, de edad, de ubicación respecto a las metrópolis, de alfabetización, etc. se fueron estableciendo o desmontando en los avatares de la historia. En vez de entenderse con un universo de individuos aislados con múltiples requerimientos y demandas, el Estado creó unos interlocutores a los que les dio el estatus de ciudadanos, a los que les asignó ciertos roles y funciones. Por otro lado, esta ciudadanía restringida desde su nacimiento, naturalizó el ámbito de intervención ciudadana sólo a los aspectos formales de lo político, referidos fundamentalmente a la representación, la delegación y la elección en los asuntos considerados del Estado, dejando por fuera otras esferas clave de lo social, por ejemplo aspectos neurales como lo económico o lo cultural, cuyos marcos de acción se asumieron bien como ajenos a la decisión estatal o bien como asuntos de índole privado.

Esta concepción de ciudadanía es un ejemplo importante que explica la aparente separación que el sentido común tiene entre cultura y política, en la que se asume que la última es la que define la suerte de los Estados, así "la cultura política latinoamericana llegó a reforzar este punto de vista, puesto que el concepto de un Estado fuerte e intervencionista, históricamente ligado a la construcción de la nación como agente primario de la transformación social, ha sido crucial en todas las versiones de proyectos populistas, nacionalistas y desarrollistas, sean conservadores o de izquierda" (Dagnino, 2001, p. 
54). La ciudadanía asociada a lo político y lo político a algunos aspectos estatales, en ausencia de cualquier otro componente, explica en parte las pobres referencias que asocian ciudadanía y elecciones, o derechos ciudadanos a posibilidades de participación, relegando este estatus a aspectos marginales, decorativos, procedimentales y secundarios en el orden de lo social.

\section{Ciudadanía y educación ciudadana}

El tema de la ciudadanía impulsada desde la escuela tuvo en Colombia, en el último siglo particulares énfasis que han tenido como constante su vínculo a lo formal y a la promoción de valores nacionales. María Teresa Uribe $(1996,1998)$ realiza una interesante revisión a propósito de su evolución en el país durante el siglo XIX y XX. Lejos de cualquier clasificación unívoca o estática, plantea para la existencia de una ciudadanía mestiza fruto de lo diferentes procesos históricos vividos en el país. Inicialmente se destaca en el proceso posindependentista la existencia de una ciudadanía colectiva, ligada a lo local, a los vínculos territoriales, ajena a la comunidad política aunque no a las lógicas de representación, que produjo una identificación entre vecino y ciudadano. Aunque aquella naciente ciudadanía era diferenciada ${ }^{3}$, fue el requisito previo para tener acceso a la comunidad política, pues era la adscripción a una comunidad concreta la que convertía a un sujeto individual en ciudadano. "No se pertenecía a una nación, que era sólo un referente abstracto, sino a un colectivo histórico con fuerte arraigo en el pasado, a un cuerpo preexistente de carácter estamental, corporativo o territorial" (Uribe, 1998, p. 33). Además, según la autora, el voto nunca expresó una imagen pluralista de nación, al contrario, los partidos -que no existían constitucionalmente- fueron percibidos como facciones que atentaban contra la nación, "como algo que la democracia debía corregir para poder subsistir y afianzarse" (Uribe, 1996, p. 74). Esta negación del pluralismo y del conflicto, expresada en la prohibición de los partidos, contrastaba con la reglamentación detallada de los procesos electorales que marcará en adelante la cultura política del país; actas, espacios específicos, es-

3 "No era lo mismo, por lo tanto, ser vecino-ciudadano de la capital del país o de los principales centros provinciales que ser de un pequeño poblado o aldea alejada. La ciudadanía era no solo diferencial por los requisitos exigidos para votar sino también de acuerdo con la localización, el territorio y la condición de vecino" (Uribe, 1996, p. 70). crutinios, delegados, ajuste a la norma... se convertirán en símbolos democráticos en el imaginario ciudadano.

A mediados del siglo XIX, a este ciudadano colectivo se le opone un radicalismo liberal desde un gobierno que defiende el voto secreto, universal y directo sin restricciones de ninguna índole. Dichas medidas provocaron fuertes reacciones a pesar que sus principios se difundieron en capas medias e intelectuales, también se materializaron en las primeras Constituciones de la segunda mitad del siglo. Según la autora, presionados por las circunstancias y la guerra civil, la dirigencia radical en el poder se vio obligada a hacer pactos y concesiones a grupos y sectores que vieron amenazados sus privilegios, de allí que la estrategia implementada fuera favorecer el federalismo para descentralizar los problemas y particularizar las soluciones. Derrotado en 1885 , el proyecto radical cede sus intenciones a la Regeneración, cuyo propósito fundamental fue la instauración de un régimen centralista, presidencialista, unitario y confesional del poder y la administración, en tal sentido se resucita el voto indirecto, la separación de los derechos civiles y políticos y unos mínimos de renta e ilustración a los potenciales electores.

Ciudadanía sacra es el nombre que acuña Uribe para referirse a esta forma de ciudadanía que elevaba la moral privada al ámbito público, ella "contribuye a otorgarle un cierto sentido teológico y trágico; de salvación del mundo y de cruzada contra el mal; de preservación de lo propio y de temor frente al otro, cultural o político, que pudiera significar alguna forma de cosmopolitismo o de pluralidad social" (Uribe, 1998, p. 39).

Dice la autora que ya en el siglo XX se pusieron las bases de lo que serían los derechos sociales y la ampliación de los derechos políticos en Colombia. Los procesos de urbanización e industrialización sucedidos desde 1930, aportaron a la disolución de los vínculos tradicionales y los viejos comunitarismos, empero, no se compensaron con la conformación de un modelo cívico ni de un orden político de corte moderno.

Por su parte, el historiador Jorge Orlando Melo (2001) al ilustrar las contradicciones entre el formalismo y la realidad en la legislación colombiana en cuanto a derechos ciudadanos, recuerda que los líderes de la naciente república en el siglo XIX tuvieron temprana conciencia del problema de la civilización y de educación cívica que debían afrontar. Así, los rituales de siembra de árboles y la escritura de catecismos republicanos o el uso del 
término ciudadano para referirse a todos los habitantes, fueron las preocupaciones de entonces en la enseñanza ciudadana. El autor dice que el período de 1886 a 1958 cuya constante "es el de un complejo proceso por incorporar los valores de la ciudadanía dentro de modelos políticos de origen escolástico y antiliberal" (p. 11) fue una difícil mezcla de tradición cristiana y principios liberales que tuvo fechas importantes como los cien años de la independencia, incentivó generosas transcripciones de la Constitución, enseñanza de la tradición nacional a manera de escuela de ciudadanía, enseñanza de urbanidad y normas de buena conducta.

Acabada la hegemonía conservadora, hacia 1933, inspirada por el gobierno liberal, la escuela es vuelta a ver como instrumento de instrucción cívica y se proponen nuevas medidas como la escuela de democracia, que consistía en la elección de un presidente por institución para que se estableciera el gobierno escolar. Para Melo, ya entonces se decía que no bastaba enseñar unos contenidos para preparar en una democracia real, sino que era necesario que los estudiantes aprendieran mediante la participación real, la discusión de problemas, el ejercicio de elección de unos representantes o la publicación de un periódico. Años más tarde, durante la dictadura la enseñanza de educación cívica se intentó cambiar por la Cátedra bolivariana y las cátedras de hispanidad.

Una importante investigación de Herrera, Pinilla y Suaza (2003) sobre textos escolares de principios del siglo XX, señala que los fines de la enseñanza de las ciencias sociales se direccionaban hacia la formación de ciudadanos virtuosos, mediante la unificación de valores cívicos y cristianos, en el que prevalecía la idea de unidad nacional a partir de referentes como el territorio, la ley, la religión y la iconografía patria. Al lado de la jerarquización social que se incentivaba en la escuela, "en los textos escolares subyace un ideal específico de sujeto social -de ciudadano- creado por el sector hegemónico de la sociedad y, por ende, se promueve determinado modelo de orden social y político acorde con los intereses de dicho sector" (p. 182).

La mención de los autores sirve para indicar la profunda relación que existió entre el ordenamiento político y la enseñanza escolar, pues como se ha mostrado, la escuela ha sido un espacio de modelación política deliberada con que cuenta el Estado, y por tanto, nicho de formación ciudadana. Pero ¿̇al conexión entre un modelo social específico y la formación ciudadana aún tiene vigencia? En caso de ser así ¿qué tipo de cultura política traslucen los actuales planes de educación para la ciudadanía que se promulgan en el país? ¿Qué tan efectivos son los planes de formación ciudadana que las políticas educativas pretenden implementar?

\section{Formación ciudadanía en las últimas décadas}

La educación para la ciudadanía es política pública en tanto se prescribe en las legislaciones del país. Existen normas, leyes y decretos que indican qué y cómo enseñar sobre esta materia. Un ejemplo reciente es la demanda de la Constitución de 1991, que indica que en "todas las instituciones de educación, oficiales y privadas, serán obligatorios el estudio de la Constitución y la Instrucción Cívica. Así mismo se fomentarán prácticas democráticas para el aprendizaje de los principios y valores de la participación ciudadana" (Constitución, 1991, p. 6). Aunque no se precisa lo que se entiende por cívica o qué tipo de prácticas se deben promover, nótese el énfasis en el aspecto teórico y práctico en el contexto de un capítulo dedicado a los derechos fundamentales.

Años más tarde, la Ley 115 (1994) busca darle cuerpo a disposiciones constitucionales sobre educación, aquí se apuesta por una escuela para la democracia, concretamente en el artículo 13 se señala que el objetivo de todos y cada uno de los niveles es "fomentar en la institución educativa, prácticas democráticas para el aprendizaje de los principios y valores de la participación y organización ciudadana y estimular la autonomía y la responsabilidad" (p. 6). Incluso materializa los mecanismos de participación de la comunidad educativa mediante lo que llamó gobierno escolar, en el que se especifican los procedimientos de representación estudiantil. Adicional a esto, y para darle un marco teórico que fundamente todas estas aspiraciones la misma Ley enuncia la creación del área de Constitución Política y Democracia, que aparece en el mismo ítem del área de ciencias sociales, historia y geografía. Se verifica que el ideal ciudadano vuelve a expresarse con generosidad en otra figura legal en 1994, incluso con la creación de un área académica obligatoria.

Obedeciendo a esta Ley, en 1998, el Ministerio expide los Lineamientos de los procesos curriculares de las áreas básicas, en el que tres de ellos, en mayor o en menor medida -Constitución Política y democracia, Ética y Afrocolombianidad- abordan específicamente la cuestión de la educación ciudadana. 
Los Lineamientos curriculares de Constitución Política y demgcracia (MEN, 1998c), formulan una ambigua pretensión pues en la presentación se indica que "hay quienes proponen... que estos lineamientos puedan ser apropiados por quienes se interesan en desarrollar educación ciudadana... [aunque] debe precisarse.... que no fue ésta la idea inicial" (p. 5). Se hace uso indiscriminado del término cívico y ciudadano sin aclarar si son lo mismo, pero en todo caso es explícito el documento en formular orientaciones sobre formación ciudadana en torno a tres ejes: "el desarrollo de una subjetividad para la democracia, el aporte en la construcción de una cultura política para la democracia y el conocimiento de las instituciones y la dinámica política" (p. 5). Ejes que con pequeñas modificaciones van a aparecer en los Estándares de competencias ciudadanas de 2004. También se coincide con los Estándares al decir que no es función exclusiva de la escuela la formación cívica y que incluso es precisamente fuera de ella donde la ciudadanía alcanza su cabal expresión. El texto finaliza haciendo una serie de aportes conceptuales y metodológicos en los que especifica para cada ámbito los logros y posibles ámbitos de aplicación en siete páginas de indicaciones didácticas.

Por su parte, también en 1998, los Lineamientos curriculares de ética y valores humanos (MEN, 1998a) plantean dentro de sus objetivos buscar "la formación de estudiantes y futuros ciudadanos más autónomos, que desarroIlen la capacidad de discernimiento como fundamento de una ética cívica orientada hacia la construcción de una sociedad civil más participativa, más justa y más solidaria" (p. 8). Este documento realiza una detallado recorrido de las formas y las concepciones en cuanto a educación para la ciudadanía desde los griegos hasta la actualidad. En él se opta por considerar los siguientes componentes: conocimiento, confianza y valoración de sí mismo; autorregulación; autorrealización; ethos para la convivencia; identidad y sentido de pertenencia; sentido crítico; formación ciudadana; conciencia de derechos y responsabilidades; competencias dialógicas y comunicativas; capacidad creativa y propositiva; juicio y razonamiento moral; sentimientos de vínculo y empatía y actitudes de esfuerzo y responsabilidad. Componentes que deben ser trabajados en el área propiamente dicha, en temas transversales o en el gobierno escolar; frente a la tarea evaluativa, ésta "deberá orientarse hacia la comprensión, interpretación y análisis evaluativo de los distintos aspectos y contenidos que se presentan en la vida cotidiana de la institución educativa" (p. 44).
En el ámbito propiamente de formación ciudadana el texto plantea que a la escuela le corresponde un lugar en la educación del ciudadano, "esta labor deberá estar orientada hacia la formación de subjetividades democráticas y el fortalecimiento de los espacios públicos escolares. Se deberá desarrollar en los estudiantes la autonomía y el juicio político que les permitirá participar de manera activa en los asuntos colectivos, tanto en su comunidad escolar como en ámbitos más amplios" (p. 56), para la cual se sugieren métodos, estrategias y contenidos temáticos encaminados a la construcción de la democracia escolar. Estas estrategias están presentadas en una tabla de catorce páginas, que igual que los Lineamientos de Constitución política y democracia, dan instrucciones metodológicas de implementación.

Por otro lado, también para el 98, los ahora Lineamientos curriculares para la Cátedra de estudios afrocolombianos (MEN, 1998b), aportan a este caudal de iniciativas en formación ciudadana. Afirman que "construir así la democracia desde la perspectiva del conocimiento y reconocimiento de las demás culturas, sin perder la conciencia de la singularidad de la cultura propia, compromete fundamentalmente a la educación. Es a ella a la que le corresponde formar ciudadanos y ciudadanas capaces de responder al tiempo, a la imperiosa necesidad de una conciencia nacional y mundial, y al afianzamiento de su propia identidad" (p. 2).

En el 2003 con la publicación de otros Lineamientos, los de ciencias sociales (MEN, 2003), se convoca el deseo de "educar para una ciudadanía que se exprese en un ejercicio emancipador, dialogante, solidario y comprometido con los valores democráticos que deben promoverse tanto en las instituciones educativas como en las aulas y en las clases" (p. 1). Se enuncia que la aplicación de estos lineamientos promueve la formación de ciudadanos que comprendan y participen en su comunidad de una manera responsable, justa, solidaria y democrática; mujeres y hombres que se formen para la vida. Incluso el texto de estos Lineamientos, buscando rebasar la dimensión exclusivamente cognitiva del aprendizaje social, propone dos nuevos tipos de competencias: las interpersonales y las intrapersonales.

Las competencias interpersonales o socializadoras son entendidas como "la actitud o disposición de un individuo para interactuar y comunicarse con otros, y ponerse en el lugar de esos otros, percibiendo y tolerando sus estados de ánimo, emociones, reacciones, etc., -ca- 
pacidad de descentración-. Todo ello para crear una atmósfera social posibilitante para todas y todos los involucrados en un contexto. Competencias que son vitales para los seres que nos creamos y desarrollamos en sociedad" (p. 45). Las intrapersonales o valorativas están entendidas como la capacidad de reflexionar sobre uno mismo, lo cual permite descubrir, representar y simbolizar sus propios sentimientos y emociones.

En todo este recorrido por documentos oficiales de más de una década, propios de las políticas públicas, Ilama en un principio poderosamente la atención varios aspectos en el más publicitado de ellos, el documento de los Estándares de competencias ciudadanas (MEN, 2004): primero que se diga que en el país "la formación ciudadana no ha recibido el énfasis necesario" (p. 5) cuando está visto que llevamos casi un siglo en ello; segundo se presenta como gran novedad el hecho que estos aprendizajes se puedan diseñar, implementar y evaluar4 y que se señale a la educación tradicional únicamente estuvo preocupada por el saber y no por el saber hacer (habilidades cognitivas, emocionales y comunicativas), cuando es evidente que en todos los documentos anteriores han hecho énfasis en la práctica y en la teoría; que descubra con el término de estándares unos "criterios... que permiten establecer cuáles son los niveles básicos de calidad de la educación a los que tienen derecho los niños y niñas" (p. 7), cuando las definiciones legales de años pasados establecían en sus objetivos precisamente lo mismo; y que para afirmar que "no se parte de cero" (p. 31) no cite en el recuadro dedicado a los documentos fundamentales para la formulación de estándares ni uno solo de los textos del Ministerio de Educación Nacional anteriores referidos en el presente escrito.

No tendría sentido para el objetivo de esta reflexión profundizar en elementos desarticulados visibles en los Estándares, como la ambigüedad sobre el uso de las escalas y los niveles para los grados del concepto competencia y estándar; o de las implicaciones prácticas del uso del término "juicio moral" (p. 8) en abandono de juicio ciudadano o juicio político expresado en documentos anteriores; o el hecho de evaluar unas competencias que dicen definirse en el "saber hacer" por medio de exámenes tipo lápiz y papel; o en la paradoja

4 Quizá la evaluación constituye el aspecto verdaderamente novedoso de la propuesta, dado que el país, hasta hace muy poco entró en la lógica de las de pruebas nacionales e internacionales estandarizadas y masivas de formación cívica. al haber aplicado en años anteriores evaluaciones de competencias ciudadanas basadas en estos estándares que en su momento nadie conocía.

Lejos de evidenciar grandes distancias, los Estándares ciudadanos, dejan ver incontables coincidencias con los textos Ministeriales de años pasados y se inscriben más bien en un continuo que opta por entender al sujeto como un individuo, escasamente conectado al medio, alguien que se educa en soledad y que debe dotarse personalmente de las herramientas necesarias para vivir en sociedad, invocaciones reiteradas en los documentos oficiales a la autonomía, al sí mismo, a la autorregulación, a la subjetividad, a la autorrealización y al conocimiento de los valores, confirman esta afirmación. Queda evidenciada la sentencia de Beck, en su crítica al Estado moderno que busca promover soluciones biográficas a contradicciones sistémicas (Bauman, 2001).

También la formación ciudadana oficial, pese a deslices y aparentes esquives, señala a la institución educativa como un escenario privilegiado de formación ciudadana. Órganos de participación, mecanismos de regulación, promoción de la convivencia pacífica, tramitación de los conflictos, involucramiento de la comunidad, vivencia de la democracia, etc., son términos y lógicas constantes en políticas escolares que sueñan una escuela al margen del contexto y que desconocen que la mayor parte de la cultura política nacional hoy en día se consume por fuera de ella.

\section{Modelos de ciudadanías y nación}

El rastreo hecho por las distintas iniciativas gubernamentales de los últimos lustros en Colombia permite identificar el proyecto dominante en la configuración del tipo de ciudadanía y el ideal de nación que se espera forjar en la escuela. Para ello conviene asistir a la clasificación que hacen Herrera, Pinilla, Díaz e Infante (2005) a la hora de caracterizar las distintas perspectivas de cultura política que se han dado en el país.

Para los autores, existen tres tipos de perspectivas en las que se pueden agrupar las distintas culturas políticas dadas en los últimos tiempos. Una perspectiva cívicoreligiosa, defensora del ideario católico y de los valores concomitantes la religión católica. "El ciudadano... es concebido como un atributo, una competencia, de los sujetos cercanos al virtuosismo definido por las leyes divinas y humanas" (p. 53). Aquí la formación ciudada- 
na se entiende como un proceso de acompañamiento y de ejemplo del adulto que conduce sabiamente a los estudiantes, y la tarea del maestro, un apostolado. Presente en buena parte de la legislación colombiana sobre formación ciudadana, este enfoque le da mucha fuerza a los valores en abstracto, como una esencia a conseguir luego de arduos procesos de formación y seguimiento. Se asiste al desconociendo de la dinámica y experiencia de los sujetos, promoviendo una educación axiológica y política descontextualizada, sin conflictos, sin país.

Esta imagen de la formación ciudadana en abstracto, contrasta poderosamente con unas décadas de violencia generalizada, descomposición social, incremento de las desigualdades y desplazamiento forzado que rasga profundamente a la nación real, mientras que la ciudadanía de papel, presente en estándares y competencias que se invoca en la escuela pareciera hablar de otro país.

Por otro lado, según los autores, se observa un enfoque cívico, heredero del ideario político liberal en el que se privilegia la promoción de determinadas maneras de actuar, mostrarse y saber, aquí la cultura política se concibe "como los comportamientos y actitudes con respecto a la política y los conocimientos que se posean sobre el funcionamiento del sistema político" (Herrera, Pinilla, Díaz e Infante, 2005, p. 52). No es difícil percatarse de que buena parte de las políticas educativas del país de las dos últimas décadas también se juega en este ámbito en el que la ciudadanía es el marco del deber ser, un ideal definido desde arriba al cual los estudiantes se adaptan mediante procesos de educación. Sobre esta línea lo importante es la legitimación y el reconocimiento de determinado orden social, la eliminación de cualquier tipo de conflicto, la participación en los mecanismos formales diseñados por el Estado. "El ideal de ciudadano que aquí circula, por ende, es un ciudadano virtuoso, dotado de atributos democráticos (competencias democráticas) que tiene existencia en tanto sea reconocido por el Estado, que debe acatar las directrices que éste defina y que le permitan alcanzar tal estadio de desarrollo sicosocial" (p. 52). La apropiación de este modelo, para los autores, condujo a que la cultura democrática se redujese a la creación de mecanismos institucionales de participación parecidos a los del sistema político legal. Metodológicamente para este enfoque prima la transmisión de conocimientos y la medición de la cultura política a partir de evaluaciones, pruebas censales y encuestas de opinión, "que se aplican a diferentes individuos para hacer generalizaciones en lo relacionado con las percepciones y usos de la democracia por parte de la sociedad en su conjunto (p. 53). Se entiende pues aqueIla concepción minimalista tanto del Estado como de la democracia (Escobar, Álvarez y Dagnino, 2001) que introdujo una inédita relación entre la sociedad civil y el Estado en la que la ciudadanía se equipara cada vez más a la integración individual al mercado, en detrimento y desconocimiento de lo colectivo, cuya expresión más visible es la ausencia en las políticas educativas sobre la formación ciudadana de dimensiones ligadas al conflicto, los movimientos sociales, las luchas colectivas, las reivindicaciones y un reducido espectro dado a los derechos humanos. Los documentos revisados son pobres en términos como protesta, bien común, víctimas, derechos humanos, política, resistencia, movilización, organización o lucha social. La ciudadanía oficial que se ofrece se juega en otros lugares, más limpios, más neutrales, más estilizados (Merklen, 2004).

Esta merma de lo grupal, esta preocupación dulzona por lo colectivo, por lo social en abstracto, por negar el conflicto, rastreable en las políticas y discursos estatales, es descrita lúcidamente por Norbert Lehner (2002), para quien el supuesto incremento de la libertad individual actual tiende a aparejarse con un incremento de la impotencia colectiva, "hoy en día, el individuo gana un grado de autonomía inédito al mismo tiempo que la acción colectiva se restringe a sucesivas manifestaciones de intereses focalizados" ( $p$. 11). En la misma línea Bauman (2001), sentencia que “el apartar la culpa de las instituciones y ponerla en la inadecuación del yo ayuda o bien a desactivar la ira potencialmente perturbadora o bien a refundirla en las pasiones de la autocensura y el desprecio de uno mismo o incluso a recanalizarla hacia la violencia y la tortura contra el propio cuerpo". Interesante pista para ubicar la anomia, la agresión, la desesperanza y el sinsentido.

Finalmente, Herrera, Pinilla, Díaz e Infante (2005) mencionan la perspectiva de la ciudadanías críticas, aquí "la cultura política se constituye en un concepto relacional, no inmutable, definido precisamente en la acción social de los sujetos" (p. 54). Al no partir de los esquemas teóricos previos sino de la realidad, este enfoque difícilmente cabe en las rejillas de estándares y competencias pues no concibe la ciudadanía como un estadio de la evolución social y política de los sujetos, sino como "un atributo de todo sujeto que, a partir de sus representaciones e imaginarios, se relaciona con las diversas formas de organización que 
representa la sociedad" (p. 55). Dos elementos a destacar en este enfoque: en primer lugar el reconocimiento de las historias y experiencias de los sujetos que intervienen en los procesos de formación, ya que sus historias, aprendizajes y relatos hacen parte de la subjetividad política que los habilita como ciudadanos, será aquí responsabilidad del Estado reconocer estas particularidades y construir escenarios de negociación cultural que partan de esta identificación; por otro lado, esta perspectiva reconoce que hay otros y variados espacios de formación distintos al escolar y que por tanto es una ilusión y una falacia diseñar estrategias que le entreguen a la escuela toda responsabilidad, pues la tarea del reconocimiento y la democratización también recaen en otras lugares.

\section{Referencias}

Bauman, Z. (2001). La sociedad individualizada. Cátedra: Madrid Constitución Política de Colombia (1991). Bogotá: Escuela Superior de Administración Pública.

Dagnino, E. (2001). Cultura, ciudadanía y democracia: los discursos y prácticas cambiantes de la izquierda latinoamericana. En: A. Escobar, S. Álvarez y E. Dagnino, E. (eds.). Política cultural \& cultura política una nueva mirada sobre movimientos sociales latinoamericanos (pp.51-85). Bogotá: Taurus.

Escobar, A; Álvarez, S. y Dagnino, E. (2001). "Introducción: lo cultural y lo político en los movimientos sociales latinoamericanos En: A. Escobar, S. Álvarez y E. Dagnino, E. (eds.) Política cultural \& cultura política una nueva mirada sobre movimientos sociales latinoamericanos (pp. 17-48). Bogotá: Taurus.

Gimeno, J. (2003). Volver a leer la educación desde la ciudadanía. En: J. Martínez (coord.). Ciudadanía, poder y educación (pp. 11-34). Barcelona: Graó.

Giroux, H. (1993). La escuela y la lucha por la ciudadanía. Pedagogía crítica de la época moderna. Madrid: Siglo XXI.

Herrera, M., Pinilla, A., Díaz, C. e Infante, R. (2005). La construcción de cultura política en Colombia: proyectos hegemónicos y resistencias culturales. Bogotá: Universidad Pedagógica Nacional.

Herrera, M.; Pinilla, A. y Suaza, L. (2003). La identidad nacional en los textos escolares de ciencias sociales. Bogotá: Universidad Pedagógica Nacional.

Herrera, M.; Pinilla, A. (2001). Aproximaciones a la relación entre cultura política y educación en Colombia. En: M. Herrera y C. Díaz (comps.). Educación y cultura política: una mirada multidisciplinar (pp. 59-92). Bogotá: Universidad Pedagógica Nacional, Plaza \& Janés.

LEY 115 (1994). Ley General de Educación.

Melo, J. (1989). Etnia, región y nación: El fluctuante discurso de la identidad (notas para un debate). En: J. Melo. Predecir el pasado: ensayos de historia de Colombia (81-107). Bogotá: Fundación Simón y Lola Guberek.
Queda por analizar el impacto de tantas iniciativas estatales sobre formación ciudadana, pues el hecho que porten en lo teórico un perfil cívico-liberal y religioso claro, no permite medir el alcance de dichas iniciativas en las prácticas de escolares que no sólo reciben el influjo de otros escenarios de socialización sino que decantan en sus escuelas mucho más y mucho menos de lo que las políticas pretenden. De momento, es posible afirmar, parodiando a Renan (1882), para quien el error histórico y el olvido son un factor esencial para la creación de nación, que es mucho lo que se ha olvidado y muchos a los que han negado deliberadamente en la educación ciudadana del país.
Melo, J. (2001). Educación para la ciudadanía: ¿̨nueva encarnación para un viejo ideal? En: Seminario Internacional de Educación Ciudadana, octubre. Bogotá: MEN.

MEN (1998a). Serie Lineamientos curriculares Educación Ética y valores humanos. Bogotá: MEN.

MEN (1998c). Serie Lineamientos curriculares Constitución política y democracia. Bogotá: MEN.

MEN (2003). Serie Lineamientos curriculares Ciencias Sociales. Bogotá: MEN.

MEN (2004). Estándares básicos de competencias ciudadanas. Formar para la ciudadanía... jsí es posible! Bogotá: MEN.

MEN. (1998b). Serie Lineamientos curriculares Cátedra estudios afrocolombianos. Bogotá: MEN.

Merklen, D. (2004). Pobres ciudadanos. Las clases populares en la era democrática. Buenos Aires: Gorla.

Renan, E. (1882). "¿2Qué es una nación?". Conferencia dictada en la Sorbona, París, 11 de marzo de 1882. Disponible en: http:// www.paginasprodigy.com/savarino/renan.pdf. (Fecha consulta: 06-07-10)

Santos, B. (1998). De la mano de Alicia. Lo social y lo político en la postmodernidad. Bogotá: Universidad de los Andes, Siglo de Hombre Editores.

Siede, I. (2007). La educación política. Ensayos sobre ética y ciudadanía en la escuela. Buenos Aires: Paidós.

Uribe, M. (1996). Proceso histórico de la configuración de la ciudadanía en Colombia. Revista Estudios Políticos. 9, 68-72.

Uribe, M. (1998). Órdenes complejos y ciudadanías mestizas: una mirada al caso colombiano. Revista Estudios Políticos. 12, 25-46.

Villavicencio, S. (2003). "La (im)posible república". En: A. Borón (comp.). Filosofía política contemporánea. Controversias sobre civilización, imperio y ciudadanía (pp. 81-93). Buenos Aires: CLACSO.

Zapata-Barrero, R. (2001). Ciudadanía, democracia y pluralismo cultural: hacia un nuevo contrato social. Madrid: Ántropos. 


\section{Diálogo del conocimiento}

Que la institución escolar centrada en los contenidos desconoce la realidad social, simplemente porque esta no hace parte del currículo es una inquietud que se plantea de forma recurrente. Por ello, resulta interesante el repaso que se hace en el texto por las concepciones que subyacen a los lineamientos curriculares para la formación ciudadana, como una de las responsabilidades fundamentales asignadas a la escuela.

Aunque tiene un carácter marcadamente descriptivo, el artículo esboza las posibilidades del análisis debido para pensar la escuela en el contexto de las múltiples y complejas realidades de un país de regiones cultural, étnica y geográficamente diversas, por solo mencionar los aspectos más obvios. Además, indaga por las ideas que animan las políticas estatales sobre formación ciudadana por más de un siglo de vida republicana. Señala que las subjetividades en tanto se construyen socialmente, también reflejan la cultura en la que se forjan y se reafirman, pues no podemos soslayar que al habitar los espacios, también vivimos las lógicas de esos espacios que habitamos.

Las concepciones de sociedad se encarnan en las mismas instituciones que constituyen el entramado estatal, por ello la escuela como espacio de construcción social no puede estar al margen de la realidad de la que es participe. Ella misma instituye una concepción de sociedad en la cotidianidad escolar, no tanto por los contenidos que se enseñan en sus aulas, sino por las prácticas escolares que día a día configuran la realidad de las personas, estudiantes y maestros, que habitan e interactúan durante años en esos espacios, siendo permeados por las lógicas y valores que allí circulan.

En este sentido, el artículo constituye una invitación a reflexionar sobre la importancia de las ideas en la vida de las personas y sobre el papel de la escuela en la socialización de los valores reflejados por el comportamiento colectivo. Pensemos, por ejemplo, lo que implicó el orden normativo que instituyó la Constitución de 1886 con su proyecto de país homogéneo, basado en la religión, la lengua y la autoridad, que configurara una realidad social en la que las diferencias se hicieron invisibles por efecto de las normas y su introyección en el diario vivir. Concepción que nos limitó para reconocer en la diversidad una riqueza para imaginar, vivir y construir un futuro colectivo.

Como lo señala el autor, aunque el sistema escolar no puede hacerse responsable por todas las dinámicas sociales de las que participa, si cabría reconocer la incidencia cultural que tiene la escuela en la vida de los sujetos. Solo baste recordar que la escolarización ha sido fundamental en la construcción de la idea de nación y de las identidades nacionales. Por ello, cabe preguntarnos, sobre las posibilidades reales de la escuela para contribuir a desarrollar un ethos democrático, frente a una realidad que plantea sendas contradicciones al discurso de los textos.

Por tanto, sin importar cuáles sean los discursos que se privilegien en el ámbito escolar o cuan contextualizados estén, en ningún caso pasarán de ser letra muerta mientras no se propicien las condiciones necesarias para la realización personal en el contexto social. Como una forma de ilustrar lo anterior, podríamos decir que para aprender del amor ni aun los mejores tratados tendrían un efecto pedagógico tan profundo como la experiencia misma de vivir y ser tratado afectuosamente. Así pues, las prácticas institucionales cotidianas dentro y fuera de la escuela constituyen el correlato necesario para que los valores democráticos enseñados en el aula terminen por enraizar en el pensar, sentir y vivir colectivo.

Juan Carlos Bustos 